\title{
TWO NOVEL CEBPA MUTATIONS IN A TURKISH PATIENT WITH ACUTE MYELOID LEUKEMIA
}

\author{
Tokgun $\mathrm{PE}^{1}$, Alay $\mathrm{MT}^{2}$, Atli Tekin $\mathrm{S}^{1}$, Güler $\mathrm{N}^{3}$, Tokgun $\mathrm{O}^{1}$, Demiray $\mathrm{A}^{1}$,
} Karagenc $\mathrm{N}^{1}$, Durak $\mathrm{T}^{1}$, Celik B ${ }^{3}$, Akca $\mathrm{H}^{1, *}$

*Corresponding Author: Professor Hakan Akca, Department of Medical Genetics, School of Medicine, Pamukkale University, Çamlaraltı, Denizli, Turkey 20070. Tel.: +90-258-296-48-04. Fax: +90-258-29617-65. E-mail: hakca@pau.edu.tr

\begin{abstract}
Acute myeloid leukemia (AML) was first categorized in 1976 by French, American and British researchers, and divided into eight subgroups (M0 to M7), depending on the cytochemical or histological changes in the leukemic cells. The gene mutations of FLT3-ITD, CEBPA and NPM1 are the most common that cooperate together in the prognosis of AML. The CEBPA gene that is a hematopoietic transcription factor, is located on chromosome 19q13.11, and its prevalence is between 5.0 and $14.0 \%$ in AML. The patient was referred to our clinic suffering from menorrhagia, unplanned weight loss in a month and low platelet levels, and was diagnosed with AML on clinical and laboratory examination. Here, we report a patient carrying two novel pathogenic mutations that create a frameshift mutation on the CEBPA gene, c.940_941 insCCGTCG TGGAGACGA CGAAGG and c.221_222delAC by Sanger sequencing methodology.
\end{abstract}

Keywords: Acute myeloid leukemia (AML); CEBPA gene; Novel mutation; Peripheral blood; Sanger sequencing.

\section{INTRODUCTION}

Acute myeloid leukemia (AML) is a hematological disorder, was first categorized in 1976, by French, American and British investigators, and divided into eight subgroups (M0 to M7), depending on the cytochemical or histological changes in the leukemic cells. The CEBPA

\footnotetext{
${ }^{1}$ Department of Medical Genetics, Pamukkale University, Denizli, Turkey

${ }^{2}$ Department of Medical Genetics, Cerrahpaşa University, Istanbul, Turkey

${ }^{3}$ Department of Internal Medicine, Division of Hematology, Pamukkale University, Denizli, Turkey
}

gene, a hematopoietic transcription factor, is located on chromosome $19 \mathrm{q} 13.11$, and its prevalence is between 5.0 and $14.0 \%$ in AML. The FLT3-ITD, CEBPA and NPM1 genes are the most common mutations that cooperate together in the prognosis of AML. Here, we present two novel pathogenic mutations that create a frameshift mutation on the CEBPA gene, c.940_941insCCGTCGTGG AGACGACGAAGG and c.221_222delAC by Sanger sequencing methodology, described in a 37-year-old woman suffering from menorrhagia, unplanned weight loss in a month and low platelet levels.

Acute myeloid leukemia is a hematological disorder, which could be involved in unexpected myeloid stem cell differentiation and proliferation independent from its etiology, without considering a prior hematological disorder or therapy. The World Health Organization (WHO) classified AML by evaluating morphology and immunophenotype in a clinical presentation in 2008, and this was updated in 2016 [1]. In 40.0-50.0\% of patients, conventional cyto-genetics and fluorescent in situ hybridization (FISH) methods have failed to detect chromosomal aberrations. Classifying patients in molecularly defined subgroups including CEBPA, FLT3-ITD and NPM1 mutations, are essential for prognosis [2] such as carrying a FLT3-ITD mutation indicates a bad prognosis due to high relapse ratio $[3,4]$, while NPM1 mutations without a FLT3-ITD mutation is indicative of a good prognosis [2,5].

The CCAAT/enhancer binding protein $\alpha(\mathrm{C} / \mathrm{EBP} \alpha)$ is a hematopoietic transcription factor that is also a member of the basic Zinc finger protein family in 42 and $30 \mathrm{kDA}$ sizes [6,7]. The $42 \mathrm{kDa}$ isoform contains TAD1, TAD2, DNA binding and leucine zipper domain, $30 \mathrm{kDa}$ isoform does not include the TAD1 domain [8]. Prevalence of CEBPA mutations in AML varies between 5.0 and $14.0 \%$ [9]. Although CEPBA mutations are commonly biallelic, and the most common type of these mutations includes both $\mathrm{N}$ and $\mathrm{C}$ terminal regions, their monoallelic forms are 
rare compared to the biallelic form $[2,10]$. The $\mathrm{N}$ terminal mutations are frameshifts and $\mathrm{C}$ terminal mutations are insertions within most common biallelic mutations [9]. Here, we report two new CEBPA mutations, c.940_941insCCG TCGTGGAGACGACGAAGG in the bZIP region and c.221_222delAC in the TAD1 region of the CEBPA protein, which are both frameshift mutations.

\section{CASE REPORT}

A 37-year-old woman was referred to the Haematology Department at Pamukkale University Hospital, Denizli, Turkey, with menorrhagia, unplanned weight loss in a month and a low platelet count and no family history of leukemia. Her physical examination was not sufficiently descriptive for hepatosplenomegaly/lymphadenopathy and abdominal ultrasonography was normal. The initial complete blood count showed hemoglobin $(\mathrm{Hb})$ level of $7.7 \mathrm{~g} / \mathrm{dL}$, platelet count of $30 \mathrm{~K} / \mathrm{uL}$, mean corpuscular volume (MCV) $70.4 \mathrm{~L} / \mathrm{L}$, eosinophils count of $9.2 \%$, lymphocytes count of $70.3 \%$, and neutrophils count of $7.7 \%$. Bone marrow biopsy and aspiration showed that white blood cell (WBC) differential is notable for $60.0 \%$ blasts and $30.0-40.0 \%$ blast, respectively. On flow cytometry, these blasts were immunopositive for CD34, cytoplasmic myeloperoxidase (MPO), CD 36, CD 33, CD 13, CD 117, TDT and CD24, while they were negative for CD 79a and cytoplasmic CD3. Cytogenetic analysis showed a karyotype $46, \mathrm{XX}, \operatorname{del}(12 \mathrm{p})$ [5]/46,XX[1]. Molecular analysis revealed no FLT3-ITD and NPM1 mutations, while on FISH analysis 5q31del, $\mathrm{t}(15 ; 17), 17 \mathrm{p} 13.1(\mathrm{p} 53) \mathrm{del}, \mathrm{t}(8 ; 21), \mathrm{t}(6 ; 11), 20 \mathrm{q} 12 \mathrm{del}$, inv16, $\mathrm{t}(16 ; 16)$ monosomy 7 and absence of del7q was detected. Tumor markers for CEA, CA 125 and CA 19-9 were normal.

\section{MATERIALS AND METHODS}

Genomic DNA from peripheral blood was prepared by using QIAamp DNA Blood Mini Kit (Qiagen, Hilden, Germany). The polymerase chain reaction (PCR) condi-

Table 1. Primer sequences used in the study.

\begin{tabular}{|l|l|}
\hline Primer & Sequences $\left(\mathbf{5}^{\prime}>\mathbf{3}{ }^{\prime}\right)$ \\
\hline Exon 1 F & AGG CTC GCC ATG CCG GGA GAA C \\
Exon 1 R & GGC TCC TGC TTG ATC ACC AGC \\
\hline Exon 2 F & CTA CCT GGA CGG CAG GCT GGA G \\
Exon 2 R & TCC ACC GAC TTC TTG GCC TTG C \\
\hline Exon 3 F & ATG CAC CTG CAG CCC GGT CAC \\
Exon 3 R & TAG AGT TGC CGG GCT CCC AGC T \\
\hline
\end{tabular}

F: forward; R: reverse. tions using the following primers (Table 1) were as follows: initial denaturation at $94{ }^{\circ} \mathrm{C}$ for $5 \mathrm{~min}$. followed by 35 cycles at $94{ }^{\circ} \mathrm{C}$ for 30 seconds, $58^{\circ} \mathrm{C}$ for 30 seconds, $72{ }^{\circ} \mathrm{C}$ for $1 \mathrm{~min}$., followed by $5 \mathrm{~min}$. at $72{ }^{\circ} \mathrm{C}$. Sequencing reactions were carried out using BigDye Terminator v 3.1 cycle sequencing kit (Applied Biosystems, Foster City, CA, USA) as follows: an initial denaturation at 96 ${ }^{\circ} \mathrm{C}$ for $1 \mathrm{~min}$., then 25 cycles at $96{ }^{\circ} \mathrm{C}$ for 10 seconds, 50 ${ }^{\circ} \mathrm{C}$ for 5 seconds, $60{ }^{\circ} \mathrm{C}$ for $4 \mathrm{~min}$., followed by $1 \mathrm{~min}$. at $72{ }^{\circ} \mathrm{C}$. Final purification was acquired using Sephadex. The ABI PRISM ${ }^{\circledR} 3130$ genetic analyzer (Applied Biosystems) was used for capillary electrophoresis. The all somatic and germline mutations are defined in line with the guidelines of the Human Genome Variation Society (HGVS). Mutations, variations and expressional activities were checked using in silico algorithm based databases as Clinvar (https:// www.ncbi.nlm.nih.gov/clinvar/), MutationTaster (http:// www.mutationtaster.org/), Varsome (https://varsome. com/), dbSNP [a database of single nucleotide polymorphisms (SNP)] (http://ncbi.nlm. nih. gov/snp).

\section{RESULTS}

The patient exhibited two novel CEBPA in-frame mutations in leukemic cells: c.221_222delAC and c.940_941 insCCGTCG TGG AGACGACGAAGG deletion/insertion mutations which localized on the TAD1 and bZIP regions of the CEBPA gene, respectively (Figure 1). The c.940 941 insCCGTCGTGGAGACGACGAAGG and c221 $22 \overline{2}$ delAC frameshift mutations were monoallelic [Figure 2(a) and 2(b)]. The c.221_222delAC mutation corresponds to the amino acid alteration p.Asn74Arg fs*33 that was classified as pathogenic due to resulting in a premature stop codon, while c.940_941insCCGTCGTGG AGACGACGA AGG corresponds to an insertion of more than two amino acids. These alterations have not been found in ExAC or in 1000Genomes and the SNP database of human genome variations (http://www.ncbi.nlm.nih.gov/snp). We report for the first time double-frameshift mutations together in an AML patient.

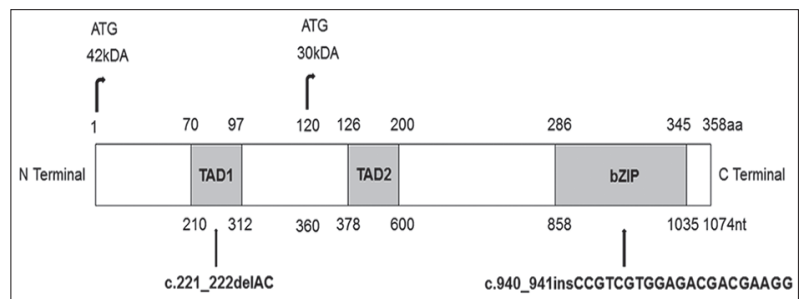

Figure 1. Schematic representation of locations of the mutations on the CEBPA gene. 


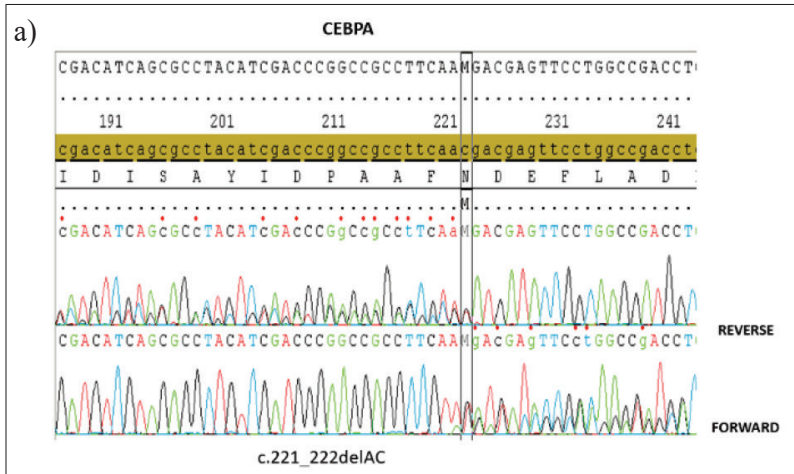

b)

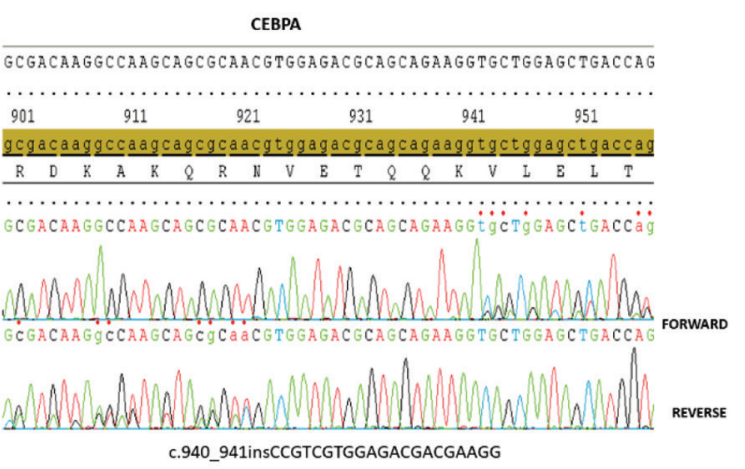

Figure 2. (a) Sequence chromatogram showing the heterozygous c.221_222delAC mutation of the CEBPA gene.

(b) Sequence chromatogram showing the heterozygous c.940_941insCCGTCGTGGAGACGACGAAGG mutation of the CEBPA gene.

\section{DISCUSSION}

Our patient revealed no FLT3-ITD and NPMI mutations but double novel CEBPA mutations. The CEBPA gene mutations without a FLT3-ITD mutation were observed to have a better prognosis when they are biallelic, therefore, this may contribute to the literature by identification of monoallelic novel mutations with a good clinical outcome. In AML patients, the rate of having chromosomal aberrations increase compared to those carrying an additional $C E B P A$ mutations. Biallelic CEBPA mutations generally result in favorable outcomes. Even limited clinical alterations show different clinical prognosis than expected CEBPA mutations, these changes are still not clearly understood in order to enlighten the clinical role of the CEBPA gene. There are limited studies about monoallelic $C E B P A$ mutations showing the importance of the relationship between mutation and clinical outcomes $[4,9,11,12]$. Two duplications on the bZIP region including c.935_991dup (p.Gln330_Leu331insGlnLysValLeuGluLeuThr SerAspAsnAspArgLeuArgLysArgValGlu Gln) and c.925_951dup (p.Leu317_Thr318insGluThrGlnGlnLysValLeu GluLeu) that localize nearest to the site of the c.940_941 insCCGTCG TGG AGA CGA CGAAGG mutation, were also reported as pathogenic for AML in online databases. Despite the fact that clinical progresses of some monoallelic mutations are similar to biallelic mutations, more cases have to be evaluated for understanding how these frameshift mutations affect the prognosis in a favorable manner.

Acknowledgments. We would like to thank all staff at the Department of Medical Genetics, Pamukkale University, Denizli, Turkey, for their technical support.

Declaration of Interest. The authors report no conflicts of interest. The authors alone are responsible for the content and writing of this article.

\section{REFERENCES}

1. De Kouchkovsky I, Abdul-Hay M. Acute myeloid leukemia: A comprehensive review and 2016 update. Blood Cancer J. 2016; 6(7): e441.

2. Lin P, Falini B. Acute myeloid leukemia with recurrent genetic abnormalities other than translocations. Am J Clin Pathol. 2015; 144(1): 19-28.

3. Schnittger S, Schoch C, Dugas M. Analysis of FLT3 length mutations in 1003 patients with acute myeloid leukemia: Correlation to cytogenetics, FAB subtype, and prognosis in the AMLCG study and usefulness as a marker for the detection of minimal residual disease. Blood. 2002; 100(1): 59-67.

4. Li GX, Wang L, Yaghmour B, Ramshingh G, Yaghmour $\mathrm{G}$. The role of FLT3 inhibitors as maintenance therapy following hematopoietic stem cell transplant. Leuk Res Rep. 2018; 10: 26-36.

5. Thiede C, Koch S, Creutzig E, Steudel C, Illmer T, Schaich M, et al. Prevalence and prognostic impact of NPM1 mutations in 1485 adult patients with acute myeloid leukemia (AML). Blood. 2006; 107(10): 4011-4020.

6. Geletu M, Balkhi MY, Peer Zada AA Christopeit M, Pulikkan JA, Trivedi AK, et al. Target proteins of C/ EB Pap30 in AML: C/EBPap30 enhances sumoylation of C/EB Pap42 via up-regulation of Ubc9. Blood. 2007; 110(9): 3301-3309.

7. Pastore F, Kling D, Hoster E, Dufour A, Konstandin NP, Schneider S, et al. Long-term follow-up of cytogenetically normal CEBPA-mutated AML. J Hematol Oncol. 2014; 7(1): 1-8.

8. Leroy H, Roumier C, Huyghe P, Biggio V, Fenaux P, Preudhomme C. CEBPA point mutations in hematological malignancies. Leukemia. 2005; 19(3): 329-334. 
9. Hughes JM, Legnini I, Salvatori B, Masciarelli S, Marchioni M, Fazi F, et al. C/EBP $\alpha-p 30$ protein induces expression of the oncogenic long non-coding RNA UCA1 in acute myeloid leukemia. Oncotarget. 2015; 6(21): 18534-18544.

10. Tawana K, Rio-Machin A, Preudhomme C, Fitzgibbon J. Familial CEBPA-mutated acute myeloid leukemia. Semin Hematol. 2017; 54(2): 87-93.
11. Kim S, Kim DH, Jang JH, Jung CW, Jang MA, Ki $\mathrm{CS}$, et al. Novel mutations in CEBPA in Korean patients with acute myeloid leukemia with a normal karyotype. Ann Lab Med. 2012; 32(2): 153-157.

12. Ram J, Flamm G, Balys M, Sivagnanalingam U, Rothberg PG, Iqbal A, et al. Index case of acute myeloid leukemia in a family harboring a novel CEBPA germ line mutation. Blood Adv. 2017; 1(8): 500-503. 